\title{
Patterns in genetic diversity of Trifolium pallescens populations do not reflect chronosequence on alpine glacier forelands
}

\author{
C Raffl ${ }^{1}$, R Holderegger ${ }^{2}$, W Parson ${ }^{3}$ and B Erschbamer ${ }^{4}$ \\ ${ }^{1}$ Institute of Ecology, University of Innsbruck, Innsbruck, Austria; ${ }^{2}$ WSL Swiss Federal Research Institute, Birmensdorf, Switzerland; \\ ${ }^{3}$ Institute of Legal Medicine, Innsbruck Medical University, Innsbruck, Austria and ${ }^{4}$ Institute of Botany, University of Innsbruck, \\ Innsbruck, Austria
}

\begin{abstract}
How does genetic diversity within populations of plants develop during primary succession on alpine glacier forelands? Theory predicts that pioneer populations are characterized by low genetic diversity due to founder effects and that genetic diversity increases within populations as they mature and recurrent gene flow occurs. However, few genetic studies have so far been carried out on plants on glacier forelands. In this study, we analysed the development of genetic diversity with time for populations of Trifolium pallescens along successional series (chronosequences) on three parallel glacier forelands in the European Alps, using neutral amplified fragment length polymorphism. No general trend in the development of genetic diversity was observed
\end{abstract}

with increasing population age: even pioneer populations harboured substantial genetic diversity. Assignment tests showed that the latter consist of a genetic sub-sample from several source areas, and not just from other populations on the glacier forelands. We also detected some long distances-that is, inter-valley gene flow events. However, gene flow was not spatially unrestricted, as shown by a weak isolation by distance pattern within glacier valleys. The actual patterns of genetic diversity along the chronosequences are a result of the combination of factors, such as gene flow and growth rate, influenced by site- and species-specific attributes. Heredity (2008) 100, 526-532; doi:10.1038/hdy.2008.8; published online 13 February 2008

Keywords: AFLPs; assignment test; colonization history; recent gene flow; primary succession

\section{Introduction}

Nature occasionally provides ideal situations to study changes in genetic structure and diversity that occur as populations grow and mature from founders. Such opportunities are often associated with situations where new habitat is formed and subsequently colonized by plants (Miles and Walton, 1993). They allow the sampling and genetic analysis of individuals from populations at different maturation stages along time series. Glacier forelands left by the retreat of permanent ice provide a corresponding situation, since they exhibit different moraines forming a spatial chronosequence. The substrate of these moraines has been exposed from ice and thus become available for plant growth for different time periods (Matthews, 1992).

On glacier forelands, each plant species has an optimum point along the time series, forming a sequence from early to late successional species. The genetic diversity of colonizing populations of both, early- and late-successional plant species, is highly affected by the number of immigrating seeds and the rates of seedling establishment (Eriksson, 1989). The latter are known to

Correspondence: Dr C Raffl, Institute of Ecology, University of Innsbruck, Technikerstrasse 25, 6020 Innsbruck, Austria.

E-mail: corinna.e.raffl@uibk.ac.at

Received 15 June 2007; revised 16 January 2008; accepted 18 January 2008; published online 13 February 2008 be low on early successional stages (NiederfrinigerSchlag and Erschbamer, 2000). On newly deglaciated terrain, that is, the pioneer situation, available safe sites for colonization by seed only represent a small proportion of the open area. As succession proceeds, vegetation cover increases and ameliorates the conditions for further seedling establishment (Stöcklin and Bäumler, 1996). As time passes, population densities of pioneer species increase and additional species of later successional stages immigrate.

While there are comprehensive studies of the changes in species composition during primary succession on glacier forelands (for example, Whittaker, 1993; Frenot et al., 1998; Mizuno, 1998), the development of genetic diversity of colonizing populations along chronosequences on glacier forelands is less investigated. Few genetic studies have been carried out on glacier forelands so far (Jumpponen, 1999; Pluess and Stöcklin, 2004; Raffl et al., 2006a). The expectations for the development of genetic diversity within populations during primary succession are laying along a continuum (Whitlock and McCauley, 1990), as a combination of effects influences the development of diversity during colonization. Genetic diversity is supposed to be low in pioneer stages because of founder events, since the earliest populations are founded by a few individuals (McCauley et al., 1995; Austerlitz et al., 1997). With ongoing succession, subsequent gene flow, in plants by either pollen or seeds, is expected to introduce new gene alleles into local 
populations. This introduction entails increasing genetic diversity in time during the initial colonization phase. Subsequently, diversity may decrease when gene flow between the newly established populations creates homogenization, and increase again, potentially reaching its maximum in long-established populations at the ecological optimum along the successional chronosequence (Slatkin, 1977; Loveless and Hamrick, 1984; Giles and Goudet, 1997). The effectiveness of gene flow on genetic diversity of local populations after establishment over time is constrained by the diversity of source populations, the proportion to which they contribute to the migrant gene pool and the population growth rates (Whitlock and McCauley, 1990; Austerlitz et al., 1997). Genetic differentiation between colonizing populations strongly depends upon how colonizing populations are formed and upon the quantitative relationship between the number of colonists founding new populations and the number of individuals exchanged between populations (Wade and McCauley, 1988). Since colonization takes place by a subset of seeds from potential source populations, genetic differentiation between newly established populations is supposed to be large. However, sub-sequential gene flow might well level out these population structure in time.

We chose Trifolium pallescens to investigate the formation of genetic diversity along chronosequences on alpine glacier forelands, as it is a characteristic plant species of this habitat type in the European Alps. The species mainly occurs on the moraines of glacier valleys and is almost absent from valley slopes and surrounding mountain ridges. It thus forms an ideal study species to investigate the genetic development of populations during primary succession. We aimed to (1) investigate the genetic diversity of $T$. pallescens populations along the chronosequence and (2) identify potential source populations of founders colonizing the pioneer sites of glacier forelands. Populations from three parallel alpine glacier valleys were investigated using amplified fragment length polymorphism (AFLP) markers (Vos et al., 1995), since they provide a fast and reliable assessment of intra-specific genetic variability and structure (Gaudeul et al., 2000).

\section{Materials and methods}

\section{Study species}

T. pallescens Schreb. is a diploid $(2 n=16)$ perennial species, known to be self-compatible, but mainly outbred and predominantly pollinated by hover flies (Hilligardt, 1993). It shows procumbent vegetative growth forming mats of about $10-15 \mathrm{~cm}$ in diameter. According to herbchronology, the oldest plants detected so far were about 11 years old (Kuen and Erschbamer, 2002). T. pallescens is a subalpine to alpine species found in Central and Southern Europe at altitudes between 1800 and $2700 \mathrm{~m}$ above sea level. Its main habitat are glacier forelands, but it also occurs along river banks, on moist scree slopes and in scarce alpine meadows on acidic bedrock (Weber, 1979). The relatively large T. pallescens seeds mostly germinate in the vicinity of mother plants (Niederfriniger-Schlag and Erschbamer, 2000), rarely reaching distances of about $6 \mathrm{~m}$. The dry flower heads are easily blown away by wind (Stöcklin and Bäumler, 1996), but almost nothing is known about the species' potential of long-distance dispersal. T. pallescens forms a persistent seed bank, where seeds remain viable for at least 5 years (E Schwienbacher, unpublished data).

\section{Study sites and sampling}

We sampled T. pallescens from three parallel, north-west exposed glacier valleys located above timberline (2200$2500 \mathrm{~m}$ above sea level) in the upper Ötztal (Tyrol, European Central Alps), that is, Gaisberg (GB; $46^{\circ} 50^{\prime} \mathrm{N}$, $11^{\circ} 03^{\prime} \mathrm{E}$ ), Rotmoos (RM; $46^{\circ} 49^{\prime} \mathrm{N}, 11^{\circ} 02^{\prime} \mathrm{E}$ ) and Langtal (LT; $46^{\circ} 48^{\prime} \mathrm{N}, 11^{\circ} 00^{\prime} \mathrm{E}$ ). The mountain ridge between GB and RM (Hohe Mut, $2670 \mathrm{~m}$ above sea level) was comparatively low with alpine grasslands to the top (Raffl and Erschbamer, 2004), while RM and LT were separated by a high, partly glaciated mountain ridge (Seelenkogel, $3420 \mathrm{~m}$ above sea level; Figure 1). The GB valley was delimited by steep valley walls on both sides. In the RM valley, the north-east (NE) facing slope was also steep, while the south-west (SW) facing slope was smoothly inclined. The LT valley was a typical U-shaped

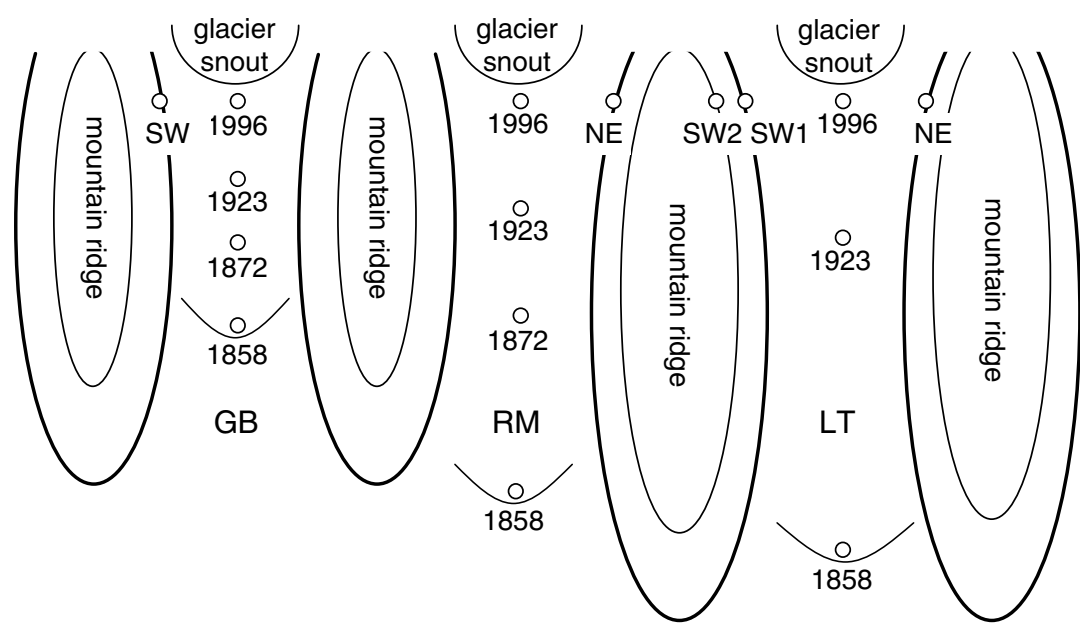

Figure 1 Sampling locations of populations of Trifolium pallescens (open circles) on three glacier forelands in the Central European Alps. 1996, 1923, 1872 and 1858: dates of moraine stages along the chronosequences; SW: south-west exposed valley slopes; NE: north-east exposed valley slopes; GB: Gaisberg valley; LT, Langtal valley; RM, Rotmoos valley. Airline distance between GB and RM is 1.4 km, and between RM and LT $3.9 \mathrm{~km}$ 
glacier valley, with extensive scree slopes on both valley sides. The three glacier forelands contained accurately dated chronosequences of moraines (Österreichischer Alpenverein, Innsbruck, Austria; unpublished data) of $1 \mathrm{~km}$ (GB), $2 \mathrm{~km}$ (RM) and $2.5 \mathrm{~km}$ (LT) length, starting with a terminal moraine dated to 1858 (Österreichischer Alpenverein; unpublished data) and proceeding with moraines from the years 1872 and 1923 and recently deglaciated terrain from 1996 (Figure 1).

Pioneer communities on the youngest moraines exhibited a vegetation cover of 10-30\% (Rudolph, 1991; Wiedemann, 1991; Raffl et al., 2006b). While in RM valley vegetation cover along the chronosequence increased to almost 90\% (Raffl et al., 2006b), it only proceeded to about $50 \%$ on the terminal moraines of 1858 in GB and LT (Wiedemann, 1991; C Raffl, personal observation). T. pallescens already occurred in the youngest stages of the chronosequences of the three studied valleys and became most prominent in the early successional stages, displacing the pioneer communities after about 40 years (Raffl et al., 2006b). It was absent from the valley slopes beyond side moraines and was completely missing from the surrounding mountain ridges (Raffl and Erschbamer, 2004).

Samples were taken along the valley bottoms on moraines representing the chronosequences (that is, 1996, 1923, 1871 and 1858). Material was also collected from the side moraines at the basis of adjacent valley slopes (Figure 1), with the exception of the NE-exposed slope in GB and the SW-exposed slope in RM, where T. pallescens did not occur. In LT, no samples could be taken from the glacier stage of 1871, since the corresponding moraine had been disturbed by flooding. Twenty-five plants, at least separated by about $10 \mathrm{~m}$, were randomly sampled within a radius of about $300 \mathrm{~m}$ at each of the 16 sampling sites (Figure 1). Samples were dried in silica gel. It was impossible to separate different populations per moraine stage or slope site, respectively. Thus, the collected 25 individuals per sampling site were pooled and treated as populations during this study.

\section{DNA extraction and AFLP fingerprinting}

Total genomic DNA was extracted from $5 \mathrm{mg}$ of dried plant tissue according to the CTAB protocol described by Doyle and Doyle (1987) with minor modifications as described by Schönswetter et al. (2002). DNA content was quantified with a fluorescent microplate reader (fmax 110, Molecular Devices Inc., Chicago, IL, USA) using PicoGreen dsDNA quantification reagent (Molecular Probes, Leicten, The Netherlands) following Juen and Traugott (2005).

The AFLP procedure was performed as described by Schönswetter et al. (2004), and PCR amplifications were carried out on a gradient Mastercycler (Eppendorf, Hilden D, Germany). The following primer combinations were used in selective amplification: EcoRI-ACA/MseICAT, EcoRI-AAG/MseI-CTT and EcoRI-AAC/MseICAGG. The fluorescence-labelled products, together with an internal size standard (ROX-500, Applied Biosystems, Foster City, CA, USA), were separated on an automated capillary sequencer (ABI3100, Applied Biosystems) and analysed using GENESCAN (Applied Biosystems). The scoring and assembly of fragments in the presence/absence of matrix was conducted with GENOGRAPHER 1.6.0 (http://hordeum.msu.montana. edu/genographer/).

\section{Statistical analyses}

All statistical analyses were based on polymorphic loci only. Genetic diversity within populations was quantified as average gene diversity $H_{\mathrm{a}}$ (index of average differences; Kosman, 2003) using ARLEQUIN 1.1. Spearman's rank correlations were calculated between moraine age (that is, time series) and average gene diversity $H_{\mathrm{a}}$ using SPSS 13.0 (SPSS; leaving out populations from valley slopes).

Analyses of molecular variance (AMOVA) were carried out with ARLEQUIN 1.1 (Schneider et al., 1997) at two different hierarchical levels, that is, among valleys and among successional stages, that is, moraine age (thus leaving out populations from valley sides in the latter analysis). To test for isolation by distance (Slatkin, 1993), matrices of direct-line geographic distances and genetic distances (pairwise $\mathrm{F}_{\mathrm{ST}}$-values from AMOVA) were correlated in a Mantel test using ARLEQUIN 1.1 with 1000 permutations for significance testing. Isolation by distance was determined for the whole data set and for each valley, separately.

Recent gene flow (Manel et al., 2005) to the 1996 pioneer situation was assessed by assignment tests using AFLPOP 1.0 (Duchesne and Bernatchez, 2002). This programme enables the statistical determination of the most likely source population of a given individual and does not rely on complete population sampling within the study area. The following settings were used: marker frequencies of zero were replaced by $(1$ /sample size +1$)$, the minimal log-likelihood difference to allocate an individual was set to 1 (it was only allocated if its allocation to a certain population was 10 times more probable than to another population), and the number of simulated genotypes to compute $P$-values was 500 .

\section{Results}

\section{Genetic diversity along successional time series}

The three primer combinations yielded a 171 polymorphic AFLP fragments from a total of 184 reproducible markers in 378 individuals of T. pallescens. Average gene diversity $H_{\mathrm{a}}$ was similar in populations (0.24-0.33; mean \pm s.e. $=0.28 \pm 0.03$; Figure 2 ). No trend of either

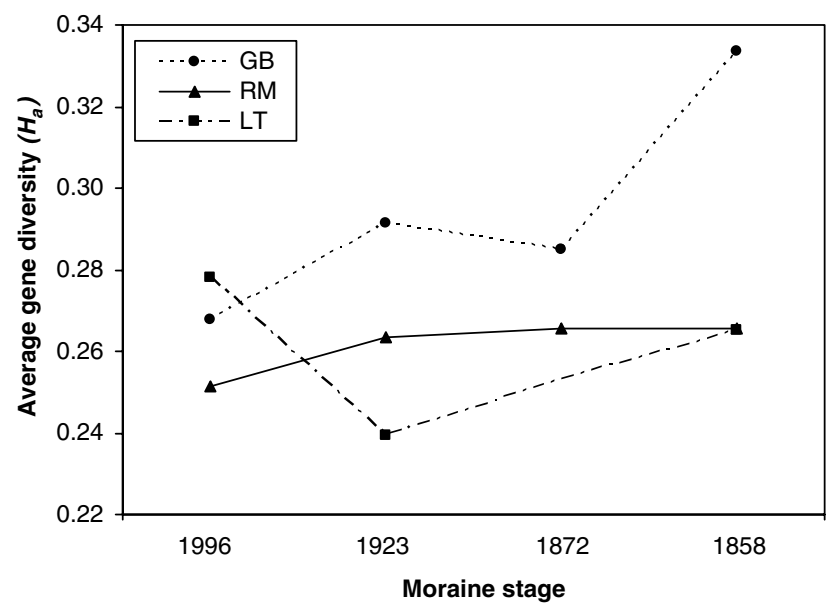

Figure 2 Average gene diversity $H_{\mathrm{a}}$ of Trifolium pallescens populations along successional series on three glacier forelands in the Central European Alps. GB, Gaisberg valley; LT, Langtal valley; RM, Rotmoos valley. 
increasing or decreasing gene diversity along the chronosequences was observed $\left(r_{\mathrm{s}}=-0.080, P=0.200\right)$. Similarly, no consistent trend was detected when considering values of $H_{\mathrm{a}}$ along the time series in each of the three valleys alone (Figure 2). An initial decrease in gene diversity in LT was opposed to an increase in GB and RM. Subsequently, average gene diversity levelled out in RM, while it increased in GB and LT with ongoing age of the corresponding moraines.

\section{Genetic differentiation among valleys and successional stages}

The AMOVA among valleys partitioned most of the genetic variation to within populations $(82.5 \%, P<0.001)$, a smaller part to populations within valleys $(12.9 \%$, $P<0.001)$ and an only small, but still significant part of variation to differentiation among valleys $(4.5 \%$, $P=0.039)$. The differentiation of stages was higher (11.3\%, $P<0.001)$, while variation within populations accounted for $84.6 \%(P<0.001)$.

A positive relationship between genetic and geographic distances among populations was present (Mantel test; $r=0.21, P=0.026)$ for the whole data set. Similarly, a positive relationship of genetic and geographic distances was also apparent in each valley, separately (RM: $r=0.742, P=0.05 ; \mathrm{GB}: \quad r=0.701$, $P=0.008$; LT: $r=0.408, P=0.05)$.

\section{Source populations for the colonization of recently deglaciated terrain}

Recent gene flow between populations established on the 1996 deglaciated moraine and potential source populations was mainly restricted to gene flow within each of the three valleys (Figure 3). At GB, the population on the SW-exposed valley slope was assigned as the most likely source population for $48 \%$ of the assigned multi-locus genotypes compared to only $12 \%$ from the glacier foreland. A more detailed analysis (data not shown) identified 20 and $4 \%$ gene flow from the glacial stages of 1923 and 1858, respectively, to the recently deglaciated terrain in GB, but none from the 1872 moraine. About $36 \%$ of the samples were unassigned at GB. At RM, the populations along the valley bottom were identified as the most likely sources of gene flow (45.8\%; Figure 3), with most stemming from the 1872 moraine $(29.2 \%$, as compared to $4.2 \%$ from the 1858 moraine; data not shown). One quarter of the individuals were not assigned. At LT, the contribution of the remaining glacier foreland to the individuals on the recently deglaciated terrain was substantial $(41.7 \%$, Figure 3$)$, but here gene flow exclusively occurred from the 1923 moraine (data not shown). In the LT valley, the SW-exposed slope was assigned as another main source area for gene flow to the recently deglaciated terrain $(45.8 \%)$, while no gene flow from the opposite valley slope was observed. About $12.5 \%$ of the individuals could not be assigned. No gene flow from the NE-exposed slopes has been detected in any of the three valleys studied.

The assignment test also identified some long-distance gene flow events from LT into both, GB and RM (Figure 3). There was $4 \%$ gene flow from the LT SWexposed slope to the pioneer stage of the glacier foreland at GB. The SW-exposed slope from LT contributed $16.7 \%$ gene flow to the recently deglaciated terrain in RM, while the total glacier foreland of LT showed $12.5 \%$ gene flow to the latter (Figure 3). There was no long-distance gene flow, neither into LT nor between GB and RM.

\section{Discussion}

Development of genetic diversity in $T$. pallescens populations on glacier forelands

Genetic diversity within T. pallescens populations from three alpine glacier valleys was similar to those of other

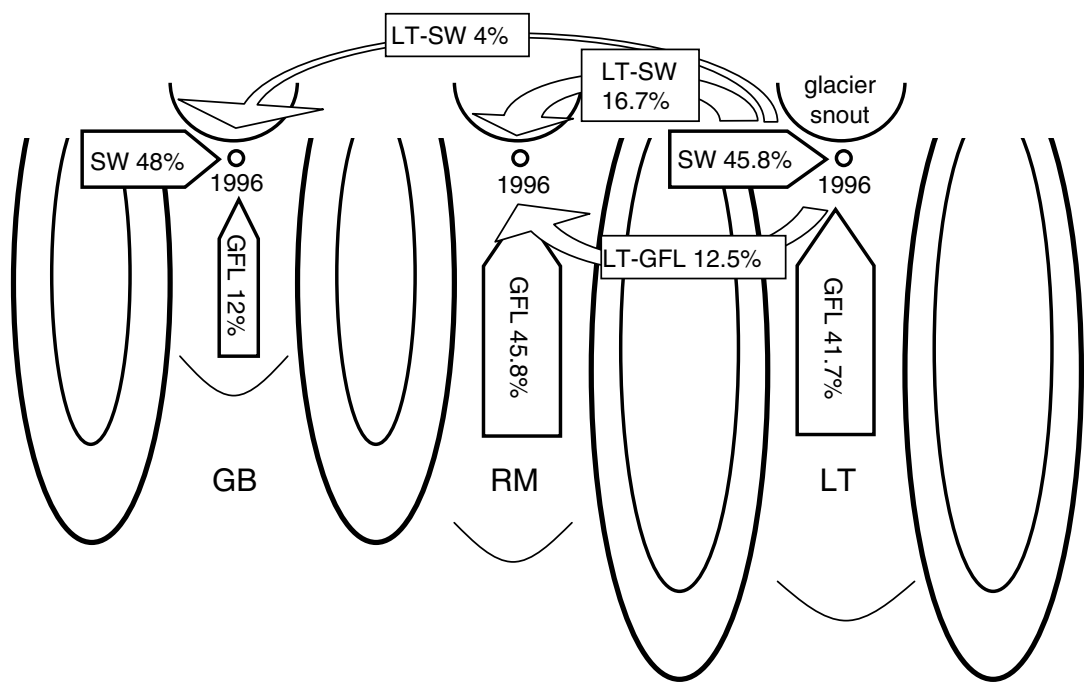

Figure 3 Recent gene flow into pioneer populations of Trifolium pallescens on recently deglaciated terrain (1996 moraine) in three glacier valleys in the Central European Alps. GB, Gaisberg valley; LT, Langtal valley; RM, Rotmoos valley; SW: south-west exposed slope; GFL, glacier foreland without the population on the youngest moraine from 1996. Arrows indicate recent gene flow as identified by assignment tests from the different source populations. From the 1996 moraine, 36, 25 and 12\% of the individuals were unassigned in the GB, RM and LT populations, respectively. 
plant species from glacier forelands, namely, Geum reptans (Pluess and Stöcklin, 2004) and Saxifraga aizoides (Raffl et al., 2006a). No general trend in the development of genetic diversity could be observed with increasing population age along the chronosequence: The most prominent feature was that genetic diversity only slightly increased between the 1996 and 1872 stages, but showed a substantial increase towards the 1858 moraine in GB (Figure 3). But, the pioneer populations of T. pallescens on recently deglaciated terrain were not characterized by a generally lower genetic diversity than that found in populations of later successional stages in all three glacier valleys studied (Figure 2). The glacier forelands in GB and RM were also investigated in a study on S. aizoides (Raffl et al., 2006a), where the development of genetic diversity along the chronosequence was similar to that detected in T. pallescens. Our results were in accordance with other studies indicating more or less constant levels of intra-populational genetic diversity through time (for example, Travis et al., 2002; Erickson and Hamrick, 2003; Lian et al., 2003; Tremetsberger et al., 2003; Pluess and Stöcklin, 2004). This pattern may be a consequence of gene dispersal, by either pollenand seed movement or inter-generation crosses within populations, in $T$. pallescens favoured by its long lifespans and/or persistent seed banks (Gaudeul et al., 2000).

Although diversity was mostly found within populations, there was a small, but significant, genetic differentiation of the populations of $T$. pallescens from different valleys $(4.5 \%)$. And there was a little larger significant genetic differentiation of populations of different stages along the successional series (11.3\%). In accordance, we found isolation by distance in each of the three valleys studied separately and in the whole data set. Short seed dispersal or pollen transport by insects is probably responsible for the isolation by distance (Gaudeul et al., 2000) observed within and between the valleys.

The above results clearly point to the important role that gene flow plays (Whitlock and McCauley, 1990) in recently colonized alpine habitats such as glacier forelands, where the total number of breeding individuals is limited. (1) The weak isolation by distance observed and the low, but significant, genetic differentiation of populations among different stages along the successional series and among valleys are clear indications that gene flow was not spatially unrestricted and not frequent enough to eradicate population differentiation. (2) The high initial genetic diversity detected in pioneer stages suggests that even gene flow into newly established populations seems substantial. Ibrahim et al. (1996) highlighted the importance of rare long-distance dispersal for both, enhanced genetic diversity in and high differentiation between founding populations. This is consistent with the review by Pannell and Charlesworth (2000), who emphasize the responsibility of gene flow from remote sources for sufficient genetic variation in newly established populations. (3) The steadily increasing genetic diversity in GB can be ascribed to continuous gene flow via pollen and-to a smaller extent-seeds from populations of T. pallescens on adjacent scree slopes. In the RM valley, genetic diversity only exhibited a slight increase in time. Unlike the situation in the GB valley, gene flow from adjacent slopes is limited because of the lack of adequate habitats of $T$. pallescens in alpine grasslands occupying the valley slopes (Raffl and Erschbamer, 2004). However, estimates of present-day gene flow based on the actual pattern in genetic diversity may be considered cautious since gene frequency differences that arise during founding events may persist for many generations (Ibrahim et al., 1996).

Besides environmental differences, species-specific ecological requirements also determine patterns of genetic diversity (Tremetsberger et al., 2003). Most alpine plants are capable of clonal reproduction in response to the harsh and unpredictable environmental conditions aggravating successful seedling establishment (Niederfriniger-Schlag and Erschbamer, 2000). Accordingly, also in $T$. pallescens, vegetative reproduction via tillers may contribute to enhanced genetic differentiation among populations. However, for the maintenance of genetic diversity within populations, the establishment of seedlings is important (Booy et al., 2000). Thus, the observed increase of diversity on older moraines may be also enhanced because the effective population size was sufficient for successful sexual reproduction in $T$. pallescens not until the 1872 stage. The pioneer S. aizoides, which was almost suppressed in older successional stages, exhibited a contrary progression of genetic diversity (Raffl et al., 2006b).

\section{Potential source populations for the colonization of the recently deglaciated terrain}

Several sources of gene flow to the populations of $T$. pallescens on recently deglaciated terrain were identified. The results by Lian et al. (2003) indicated two sequential modes of seed dispersal for population establishment; while pioneers may stem from seeds dispersed over long distances, the further establishment tends to base on short-distance dispersal of the nearest mother plant.

For $T$. pallescens, the adjacent glacier foreland was generally the most important source for gene flow into populations on recently deglaciated terrain in LT $(41.7 \%)$ and RM (45.8\%), but this proportion was much lower in GB (12\%; Figure 3). Although potential source populations were rare for $T$. pallescens on adjacent valley slopes (Raffl and Erschbamer, 2004), they provided almost as much gene flow to pioneer populations as populations on the glacier foreland (except in RM). In GB, gene flow from valley slopes accounted for $48 \%$ and for $45.8 \%$ in LT. In contrast to this situation, in T. pallescens, gene flow to recently deglaciated ground from a much larger potential source area was detected in S. aizoides including surrounding mountain ridges (Raffl et al., 2006a).

Despite the high mountain ridge in-between them, recent gene flow from LT into GB (4\%) and from RM $(29.2 \%)$ valley was found (Figure 3 ). In the only other study that investigated recent long-distance gene flow in an alpine plant, gene flow among populations from different valleys (4\%) was also found (Raffl et al., 2006a). Rare long-distance dispersal can dramatically increase gene flow during colonization (Nichols and Hewitt, 1994). According to Le Corre and Kremer (1998) the main effect of large-distance dispersal is to reduce both, the loss of diversity and the increase in genetic differentiation by preventing a pronounced effect of founder events. Thus, even low rates of long-distance dispersal potentially play an important role in the population dynamics of $T$. pallescens. Despite its attribute of small 
dispersibility (Stöcklin and Bäumler, 1996; Niederfriniger-Schlag and Erschbamer, 2000), the present genetic results suggest that the comparably large seeds of $T$. pallescens are nevertheless regularly dispersed over relatively large distances. This adds up to the growing body of genetic studies on recent or contemporary gene flow that finds much higher rates and longer distances of gene flow than that suggested by traditional ecological experiments (Nathan, 2006).

\section{Conclusions}

This study of genetic diversity on three alpine glacier foreland populations in the European Alps has given insights on probable origins of colonizing $T$. pallescens. There was recursive gene flow among populations sometimes even over larger distances. This led to substantial genetic diversity even in the youngest populations, representing a genetic sample from different source areas. Pioneer populations were not a genetic sub-sample of the yet established populations on the glacier foreland only. However, gene flow was not spatially unrestricted as indicated by a weak local isolation by distance pattern. No general trend in the development of genetic diversity was observed with the increase of plant population age. The actual patterns are a result of the combination of factors, such as gene flow and growth rate, influenced by site- and species-specific attributes.

\section{Acknowledgements}

We acknowledge the help in the field and laboratory as well as the advice by $M$ Blassnig, W Durka, E Grasserbauer, F Gugerli, M Hubmann, A Juen, H Kudrnovsky, B Lorbeg, S Mantsch, P Schönswetter, E Schwienbacher, M Traugott and M Wallinger. We also thank three anonymous referees for their valuable comments on the paper. This work was financially supported by the Austrian Science Fund (FWF; project no. P14811-B06).

\section{References}

Austerlitz F, Jung-Mueller B, Godelle B, Gouyon P-H (1997). Evolution of coalescence in times, genetic diversity and structure during colonization. Theor Pop Bio 51: 148-164.

Booy G, Hendriks RJJ, Smulders MJM, Van Groenendael JM, Vosman B (2000). Genetic diversity and the survival of populations. Plant Biol 2: 379-395.

Doyle JJ, Doyle JL (1987). Isolation of plant DNA from fresh tissue. Focus 12: 13-15.

Duchesne P, Bernatchez L (2002). AFLPOP: a computer program based for simulated and real population allocation, based on AFLP data. Mol Ecol Notes 2: 380-383.

Erickson DL, Hamrick JL (2003). Genetic and clonal diversity for Myrica cerifera along a spatiotemporal island chronosequence. Heredity 90: 25-32.

Eriksson O (1989). Seedling dynamics and life histories in clonal plants. Oikos 55: 231-238.

Frenot Y, Gloaguen JC, Cannavacciuolo M, Bellido A (1998). Primary succession on glacier forelands in the subantartic Kerguelen Islands. J Veg Sci 9: 75-84.

Gaudeul M, Taberlet P, Till-Bottraud I (2000). Genetic diversity in an endangered alpine plant, Eryngium alpinum L.
(Apiaceae), inferred from amplified fragment length polymorphism markers. Mol Ecol 9: 1625-1637.

Giles BE, Goudet J (1997). Genetic differentiation in Silene dioica metapopulations: estimation of spatiotemporal effects in a successional plant species. Amer Nat 149: 507-526.

Hilligardt M (1993). Durchsetzungs- und Reproduktionsstrategien bei Trifolium pallescens Schreb. und Trifolium thalii Vill Flora 188: 93-116.

Ibrahim KM, Nichols RA, Hewitt GM (1996). Spatial patterns of genetic variation generated by different forms of dispersal during range expansion. Heredity 77: 282-291.

Juen A, Traugott M (2005). Detecting predation and scavenging by DNA gut-content analysis: a case study using a soil insect predator-prey system. Oecologia 142: 344-352.

Jumpponen A (1999). Spatial distribution of discrete RAPD phenotypes of a root endophytic fungus, Phialocephala fortinii at a primary successional site on a glacier forefront. New Phytol 141: 333-344.

Kosman E (2003). Nei's genetic diversity and the index of average differences are identical measures of diversity within populations. Plant Pathol 52: 533-535.

Kuen V, Erschbamer B (2002). Comparative study between morphology and age of Trifolium pallescens in a glacier foreland of the Central Alps. Flora 197: 379-384.

Le Corre V, Kremer A (1998). Cumulative effects of founding events during colonisation on genetic diversity in an island and stepping-stone model. J Evol Biol 11: 495-512.

Lian C, Oishi R, Miyashita N, Nara K, Nakaya H, Wu B et al. (2003). Genetic structure and reproduction dynamics of Salix reinii during primary succession on Mount Fuji, as revealed by nuclear and chloroplast microsatellite analysis. Mol Ecol 12: 609-618.

Loveless MD, Hamrick JL (1984). Ecological determinants of genetic structure in plants populations. Annu Rev Ecol Syst 15: 65-95.

Manel S, Gaggiotti OE, Waples RS (2005). Assignment methods: matching biological questions with appropriate techniques. Trend Ecol Evol 20: 136-142.

Matthews JA (1992). Plant succession: patterns and environmental factors. In: Matthews JA (ed). The Ecology of Recently Deglaciated Terrain. A Geological Approach to Glacier Forelands and Primary Succession. Cambridge University Press: Cambridge. pp 182-189.

McCauley DE, Raveill J, Antonovics J (1995). Local founding events as determinants of genetic structure in a plant metapopulation. Heredity 75: 630-636.

Miles J, Walton DWH (eds) (1993). Primary Succession on Land. Blackwell: London.

Mizuno K (1998). Succession of alpine vegetation in response to glacial fluctuations of Tyndall glacier, Mt. Kenya, Kenya. Arct Alp Res 30: 340-348.

Nathan R (2006). Long-distance dispersal of plants. Science 313: 786-788.

Nichols RA, Hewitt GM (1994). The genetic consequences of long distance dispersal during colonization. Heredity $\mathbf{7 2}$ 312-317.

Niederfriniger-Schlag R, Erschbamer B (2000). Germination and establishment of seedlings on a glacier foreland in the Central Alps. Arct Antarc Alp Res 32: 270-277.

Pannell JR, Charlesworth B (2000). Effects of metapopulation processes on measures of genetic diversity. Phil Trans Roy Soc 355: 1851-1864.

Pluess AR, St J (2004). Population genetic diversity of the clonal plant Geum reptans (Rosaceae) in the Swiss Alps. Amer J Bot 91: 2013-2021.

Raffl C, Erschbamer B (2004). Comparative vegetation analyses of two transects crossing a characteristic glacier valley in the Central Alps. Phytocoen 34: 225-240.

Raffl C, Mallaun M, Mayer R, Erschbamer B (2006b). Succession pattern and diversity changes in a glacier valley (Central Alps, Austria). Arct Antarc Alp Res 38: 421-428. 
Raffl C, Schönswetter P, Erschbamer B (2006a). 'Sax-sess'genetics of primary succession in Saxifraga aizoides on two parallel glacier forelands'. Mol Ecol 15: 2433-2440.

Rudolph D (1991). Vergleichende Studien zur Vegetationsentwicklung im Vorfeld des Rotmoosferners/Ötztaler Alpen. MSc Thesis, University of Giessen: Giessen.

Schneider S, Kueffer JM, Roessli D, Excoffier L (1997). ARLEQUIN 1.1: A Software for Population Genetic Analysis. Genetics and Biometry Laboratory University of Geneva: Geneva.

Schönswetter P, Tribsch A, Niklfeld H (2002). Several Pleistocene refugia detected in the high alpine plant Phyteuma globulariifolium Sternb. Hoppe (Campanulaceae) in the European Alps. Mol Ecol 11: 2637-2647.

Schönswetter P, Tribsch A, Stehlik I, Niklfeld H (2004). History of high alpine Ranunculus glacialis (Ranunculaceae) in the European Alps in a comparative phylogeographical context. Biol J Linn Soc 81: 183-195.

Slatkin M (1977). Gene flow and genetic drift in a species subject to frequent local extinctions. Theor Pop Biol 12: 253-262.

Slatkin M (1993). Isolation by distance in equilibrium and nonequilibrium populations. Evolution 47: 264-279.

Stöcklin J, Bäumler E (1996). Seed rain, seedling establishment and clonal growth strategies on a glacier foreland. J Veg Sci 7: 45-56.
Travis SE, Proffitt CE, Lowenfeld RC, Mitchell TW (2002). A comparative assessment of genetic diversity among differently-aged populations of Spartina alterniflora on restored versus natural wetlands. Rest Ecol 10: 37-42.

Tremetsberger K, Stuessy TF, Samuel RM, Baeza CM, Fay MF (2003). Genetics of colonization in Hypochaeris tenuifolia (Asteraceae, Lactuceae) on Volcán Lonquimay, Chile. Mol Ecol 12: 2649-2659.

Vos P, Hogers R, Bleeker M, Reijans M, van de Lee T, Bleeker M et al. (1995). AFLP: A new technique for DNA fingerprinting. Nucl Acid Res 23: 4407-4414.

Wade JW, McCauley DE (1988). Extinction and recolonization: their effects on the genetic differentiation of local populations. Evolution 42: 995-1005.

Weber HE (ed) (1979). Hegi G, Illustrierte Flora von Mitteleuropa (Bd 4.3). Weißdorn: Jena, Germany.

Whitlock MC, McCauley DE (1990). Some population genetic consequences of colony formation and extinction: genetic correlations within founding groups. Evolution 44: 1717-1724.

Whittaker RH (1993). Plant population patterns in a glacier foreland succession: pioneer herbs and later-colonizing shrubs. Ecography 16: 117-136.

Wiedemann T (1991). Die Entwicklung von Vegetation und Boden im Vorfeld des Gaisbergferners/Ötztaler Alpen. MSc Thesis, University of Gießen: Gießen, Germany. 